\title{
A CULTURA, O MEIO AMBIENTE E A EDUCAÇÃO AMBIENTAL NAS LETRAS MUSICAIS DO CARIMBÓ DE MARAPANIM (PA)
}

Raynon Joel Monteiro Alves ${ }^{1}$

Altem Nascimento Pontes ${ }^{2}$

Resumo: Este estudo objetivou analisar as letras musicais do carimbó de Marapanim-PA relacionadas à cultura, meio ambiente e Educação Ambiental. Estas composições musicais foram adquiridas junto aos representantes dos grupos locais de carimbó: Japiim, Os originais, Flor do Mangue e Flor da Cidade. Verificou-se que as referidas letras musicais expressavam a religiosidade, os costumes, as crenças locais e, na maioria das vezes, o cotidiano do homem rural e do seu trabalho agroextrativista, além de incluir a contemplação e proteção dos recursos naturais em seus versos poéticos e, em alguns casos, até estimulando o senso crítico dos ouvintes em relação aos problemas socioambientais, o que pode ser um importante instrumento de difusão e debate da EA nos distintos espaços de ensino.

Palavras-chave: Educação; Composições Musicais; Patrimônio Imaterial Brasileiro. 


\section{Introdução}

O carimbó é uma manifestação artística que compreende o gênero de música e dança popular da região Norte do Brasil, originado pela fusão de elementos indígenas, africanos e ibéricos, e hoje representa a ampla diversidade de expressões culturais dos povos da Amazônia Brasileira (GOMES, 2011; GABBAY, 2012). Somente, em 11 de setembro de 2014, foi declarado Patrimônio Cultural Imaterial Brasileiro pelo Conselho Consultivo do Patrimônio Cultural, órgão vinculado ao Instituto do Patrimônio Histórico e Artístico Nacional - IPHAN (BRASIL, 2014).

Historicamente, o carimbó foi produzido e consumido por setores populares, interioranos e/ou suburbanos, folcloristas e intelectuais, excedendo posteriormente a indústria cultural local e regional (COSTA, 2011). A modernização desse estilo musical resultou na sua popularização entre os moradores da capital (Belém) e, em seguida, de outras regiões do país, o que contribuiu para que o mesmo se tornasse um dos maiores representantes da identidade regional e da cultura popular do Estado do Pará (FUSCALDO, 2015).

Predominantemente paraense, o carimbó é uma das manifestações culturais tradicionais, principalmente, produzida por comunidades ribeirinhas e rurais (MONTEIRO, 2012; FUSCALDO, 2015). Neste contexto, o município de Marapanim-PA é conhecido como a capital desse ritmo e dança, onde anualmente ocorre o Festival do Carimbó na sede municipal (BEZERRA, 2011).

Em Marapanim, assim como em todo o Estado do Pará, a dança consiste numa reunião de pessoas que dançam em pares, onde o homem corteja a mulher (BLANCO, 2004). Por sua vez, a música é produzida da forma clássica, por meio de grandes tambores de madeira oca, denominados carimbós ou curimbós, além de alguns instrumentos de sopro, de corda e de percussão, cujas letras geralmente retratam o cotidiano do homem do campo e do pescador (COSTA, 2010) e outros elementos culturais, religiosos, místicos e de exaltação e cuidado com a Amazônia.

Neste contexto, pode-se considerar a música como uma estratégia de ensino sob a perspectiva da Educação Ambiental - EA (MARIN; PEREIRA, 2009), uma vez que é possível identificar em algumas composições musicais do local a ênfase em problemas socioambientais, valorização da cultura, do modo de vida amazônico, e em ideias preservacionistas/conservacionistas quanto aos recursos naturais. Deste modo, a mídia, em sua totalidade, tornouse atualmente um importante veículo de propagação da EA entre a população, visando formar indivíduos com diferentes modos de ser e viver na contemporaneidade (VIEIRA; HENNING, 2012).

Por sua vez, a EA surge como um processo socioeducativo que visa a construção de valores, conceitos, habilidades e atitudes nas pessoas como forma de entender a realidade e nela atuar de maneira consciente e responsável, tendo em vista a qualidade de vida individual, coletiva e planetária (LOUREIRO, 2002). A EA pode ser caracterizada por concepções, como as 
propostas por Silva e Campina (2011): a conservadora, de base ambientalista, presença de vínculos afetivos do homem com a natureza, enfoque na valorização e na proteção do meio ambiente; a pragmática, visando solucionar problemas ambientais por meio da legislação estabelecida e integrar desenvolvimento econômico e sustentabilidade; e, por último, a crítica, que compreende uma visão interdisciplinar para o entendimento da problemática socioambiental, mudança de comportamento coletivo e a formação de sujeitos ecológicos.

Diante do exposto, o presente estudo pretendeu analisar as letras das músicas de carimbó do município de Marapanim-PA com ênfase nos elementos pertinentes à cultura, meio ambiente e concepções de Educação Ambiental.

\section{Material e métodos}

A área de estudo compreendeu o município de Marapanim-PA, conhecido legalmente como a Capital do Carimbó por meio do Conselho Deliberativo do IPHAN. Para isso, foram importantes os relatos orais que informaram a procedência dessa arte na comunidade rural de Maranhãozinho, e, hoje, o referido município apresenta dezenas de mestres, músicos, dançarinos, aprendizes e brincantes (MMA, 2014). Além disso, desde 2003, foi criado o projeto "Festival do Carimbó de Marapanim: o Canto Mágico da Amazônia" com o intuito de resgatar, valorizar e divulgar a cultura de um povo amazônico - evento que vem ocorrendo continuamente, uma vez por ano na sede municipal.

Como procedimentos metodológicos, inicialmente, foi realizada uma pesquisa bibliográfica sobre o tema para norteá-lo e para a fundamentação teórica. Posteriormente, durante o mês de julho de 2015, realizou-se um levantamento de músicas de carimbó relacionadas à cultura, meio ambiente e EA junto aos representantes dos grupos folclóricos de Marapanim: Japiim, Os originais, Flor do Mangue e Flor da cidade.

As composições musicais foram analisadas e categorizadas de acordo com a temática proposta (cultura, meio ambiente e concepções de EA). Neste último caso, consideraram-se as concepções estabelecidas por Silva e Campina (2011): conservadora, pragmática e crítica.

\section{Resultados e discussão}

A música é uma forma de criação e manifestação cultural presente em distintos espaços, constituindo-se em um processo identitário (NABAES, 2008). O carimbó, enquanto música e poesia, geralmente está relacionado ao modo de vida do homem rural, quando produzido nos interiores de Belém-PA, pois retrata a realidade socioambiental e cultural de determinada localidade. Assim, considera-se que a percepção do indivíduo (compositor musical, nesse caso) contribui para os processos criativos (MARIN; PEREIRA, 2009), incorporando elementos cotidianos às músicas.

revista brasileira educação ambiental 
Nessa perspectiva, conforme o Quadro 1 , os versos musicais podem retratar a situação diária de agricultores $(A, B)$ e de pescadores (C, D). Afinal, na zona costeira do Estado do Pará é bastante expressivo o número desses trabalhadores, pois segundo Furtado et al. (2006), na região as atividades de subsistência e econômicas compreendem a pesca, lavoura, coleta, extrativismo e serviços primários por meio da mobilização dos recursos naturais disponíveis na natureza. O carimbó, assim como outras manifestações que representam cada município paraense, surge das tarefas do dia-a-dia entre o rio e a floresta, e se intensifica nos momentos festivos das comunidades em homenagem a personalidades, santos e eventos (JASTES, 2009).

Quadro 1: Letras musicais que retratam o modo de vida dos trabalhadores de Marapanim.

\begin{tabular}{|c|c|c|c|}
\hline Grupo Japiim (A) & $\begin{array}{l}\text { Grupo Flor da } \\
\text { Cidade (B) }\end{array}$ & $\begin{array}{l}\text { Grupo Os Originais } \\
\text { (C) }\end{array}$ & $\begin{array}{l}\text { Grupo Flor da Cidade } \\
\text { (D) }\end{array}$ \\
\hline $\begin{array}{l}\text { Menina da roça } \\
\text { Que mora em palhoça } \\
\text { Que vai pro retiro } \\
\text { E na sua cintura } \\
\text { Leva o tipiti } \\
\text { Leva o aguidal } \\
\text { Também a peneira } \\
\text { E na sua maneira } \\
\text { Tirar o tipiti } \\
\text { Menina da roça } \\
\text { Vai descendo a ladeira } \\
\text { Vai pelo caminho } \\
\text { Do igarapé } \\
\text { Na cabeça o paneiro } \\
\text { Cheio de mandioca } \\
\text { Pra tirar a tapioca } \\
\text { Pra tomar o café }\end{array}$ & $\begin{array}{l}\text { (...) } \\
\text { O homem põe a roça } \\
\text { E trabalha o dia todo } \\
\text { Planta arroz, planta } \\
\text { feijão } \\
\text { Jerimum e melancia } \\
\text { (...) }\end{array}$ & $\begin{array}{l}\text { Quando é de } \\
\text { madrugada } \\
\text { Eu saio pra ir pescar } \\
\text { Embarco no meu } \\
\text { veleiro } \\
\text { E saio nas ondas do } \\
\text { mar (...) }\end{array}$ & $\begin{array}{l}\text { Eu sou pescador } \\
\text { Da terra também } \\
\text { conheço } \\
\text { Sou filho de lavrador } \\
\text { Isso foi um bom } \\
\text { começo } \\
\text { (...) }\end{array}$ \\
\hline
\end{tabular}

Fonte: Dados da pesquisa.

De acordo com o Quadro 2, verifica-se que as composições musicais também podem fazer menção à biodiversidade amazônica sob o aspecto natural, de embelezamento da paisagem e de contemplação humana $(E, F)$ ou tratar das múltiplas formas de vida, como as encontradas em áreas estuarinas e de manguezais, como: crustáceos e moluscos $(G)$, que são típicas da alimentação humana local. Neste sentido, pode-se inferir que a poesia - transformada em música de carimbó - é revestida de uma poeticidade inspirada na natureza (MONTEIRO, 2012) e suas características ambientais.

Quadro 2: Letras musicais que retratam a biodiversidade amazônica em Marapanim.

\begin{tabular}{|c|c|c|}
\hline Grupo Os Originais (E) & Grupo Flor da Cidade (F) & Grupo Flor do Mangue (G) \\
\hline $\begin{array}{l}\text { Eu fui na floresta no meio da } \\
\text { bicharada } \\
\text { É muito bonito quando chega a } \\
\text { madrugada } \\
\text { Canta tudo a passarada, papagaio } \\
\text { e nambu } \\
\text { (...) }\end{array}$ & $\begin{array}{l}\text { (...) As cores a natureza dá } \\
\text { Beleza que a vida tem } \\
\text { A onda que balança o mar } \\
\text { Da onde a borboleta vem }\end{array}$ & $\begin{array}{l}\text { Mexilhão é um marisco } \\
\text { Serve de alimentação } \\
\text { O siri e o caranguejo } \\
\text { O turu e o camarão } \\
\text { A ostra mora na pedra } \\
\text { O sururu no manguezal } \\
\text { O caranguejo mora na lama } \\
\text { E o turu mora no pau (...) }\end{array}$ \\
\hline
\end{tabular}

Fonte: Dados da pesquisa.

Revbea, São Paulo, V. 12, № 1: 155-164, 2017. 
Conforme o Quadro 3, ainda na perspectiva de contemplação e valorização do meio ambiente, há músicas que enfatizam a territorialidade num contexto local $(G)$ e regional $(H)$ com suas respectivas particularidades naturais e culturais, que são considerados atrativos turísticos. É perceptível a interação do homem amazônico com a geografia amazônica, uma vez que o cotidiano da população é inerente à cultura de um determinado lugar (CAMPELO; ALMEIDA, 2012).

Quadro 3: Letras musicais que caracterizam o município de Marapanim-PA e a capital

\begin{tabular}{|l|l|}
\multicolumn{2}{c|}{ paraense - Belém. } \\
\hline \multicolumn{1}{|c|}{ Grupo Flor do Mangue (G) } & \multicolumn{1}{c|}{ Grupo Os originais (H) } \\
\hline Marapanim é terra boa & Belém, cidade bonita \\
E o lazer é o carimbó & É uma terra hospitaleira \\
É uma ilha praiana & Tem coisas maravilhosas \\
Pertinho de Arapijó (...) & É a cidade das mangueiras \\
& \\
O orgulho que nós temos & Tem jogo de futebol \\
Aqui de Marapanim & Que alegra a multidão \\
É ter as nossas lindas praias & Na Augusto Montenegro \\
Marudá e do Crispim. & No estádio do Mangueirão (...) \\
& Belém, cidade bonita \\
& É a capital do Pará \\
& Em frente do Ver-o-Peso \\
& Tem a Baía do Guajará \\
& \\
\hline
\end{tabular}

Fonte: Dados da pesquisa.

No Quadro 4, nota-se que as letras musicais podem estar associadas à religiosidade, como, por exemplo, referindo-se ao Círio da Padroeira do povo católico paraense: o de Nossa Senhora de Nazaré (I), mas também podem fazer alusão aos seres "encantados" dos mitos que fazem parte da vida dos moradores locais, como é o caso da sereia $(\mathrm{J})$. Sobre isso, ressalta-se que grande parte do território amazônico, como na Microrregião do Salgado Paraense, onde está situado o município de Marapanim, além das religiões conhecidas, há a pajelança cabocla e a encantaria amazônica (FUSCALDO, 2015).

Quadro 4: Letras musicais que fazem referência à religião, mitos e crenças de Marapanim.

\begin{tabular}{|l|l|}
\hline \multicolumn{1}{|c|}{ Grupo Os originais (I) } & \multicolumn{1}{c|}{ Grupo Flor da cidade (J) } \\
\hline (...) Tem festa dos paraenses & (...) Hoje eu vou na praia \\
Ó Círio de Nazaré & Me deitar na areia \\
É a grande procissão & Ver a brisa do mar \\
Que sai da lgreja da Sé (...) & E o canto da sereia \\
& \\
\hline
\end{tabular}

Fonte: Dados da pesquisa. 
Considera-se a cultura popular como veículo de comunicação usada pelo povo (CAMPELO; ALMEIDA, 2012), bem como a capacidade que a música tem em sensibilizar um sujeito que entoa ou apenas escuta um trecho musical (MARIN; PEREIRA, 2009). O carimbó de Marapanim, em particular, visa não apenas oferecer divertimento aos brincantes e simpatizantes, manter viva a cultura e tradição da região, mas, em especial, conscientizar os ouvintes por meio da poeticidade musical que apela a favor da natureza - que lhe é fonte de inspiração na composição de muitas músicas.

Quanto às mensagens de $E A$, verificou-se que a concepção conservadora, estudada por Sauvé (2005), Marpica (2008) e Silva e Campina (2011), é a mais encontrada nas composições musicais do carimbó marapaniense, pois estas advertem a adoção de atitudes ambientalistas em relação aos recursos naturais por meio de um guia de comportamentos, além de fomentar a contemplação, valorização e proteção da natureza. Nessa concepção da EA são transmitidas práticas simplistas, atitudes ecologicamente corretas e a reformulação da relação homem-natureza (FONSECA; OLIVEIRA, 2011).

Neste contexto, citam-se como exemplos as músicas que retratam os problemas ambientais que decorrem de ações antrópicas, de acordo com o Quadro 5, como as queimadas ( $L, M)$, que ocorrem no município por meio da agricultura tradicional de corte e queima e/ou pela expansão imobiliária constante e, em geral, ilegal. Concomitantemente, as composições musicais emitem aos ouvintes mensagens sobre a preservação e a conservação dos recursos naturais para o bem comum das gerações presentes e futuras $(N)$.

Quadro 5: Letras musicais que se referem à problemática ambiental da região e mensagens de EA conservadora.

\begin{tabular}{|l|l|l|}
\hline \multicolumn{1}{|c|}{ Grupo Os originais (L) } & \multicolumn{1}{|c|}{ Grupo Flor do mangue (M) } & \multicolumn{1}{|c|}{ Grupo Japiim (N) } \\
\hline (...) Vamos ter cuidado com a & O homem fazendo queimadas & Vou contar-lhe uma história \\
vida dos animais & Eue causa preocupação \\
Não queimem as nossas & Vegetação e animais & Vou falar da natureza \\
florestas & Nas queimadas estão morrendo & Patrimônio da nação \\
Que para nós é bom demais & & \\
Essa riqueza tem muita & Se o homem pensasse bem & Vamos cuidar, minha gente \\
vegetação & Vamos cuidar \\
Melhora nossa saúde e de não aconteceria & Vegetação e animais & Da nossa natureza \\
todos os irmãos. & Pas queimadas não morria & Pro homem não acabar \\
(...) As nossas florestas têm & $(\ldots)$ & Tudo está ameaçado \\
muita riqueza, & E nós devemos cuidar \\
A nossa Amazônia, uma beleza & & Para que nossos filhos \\
Vamos ter cuidado para não & Tenham onde morar \\
acabar & \\
A grande riqueza do nosso Pará & \\
\hline
\end{tabular}

Fonte: Dados da pesquisa.

No entanto, é perceptível a inserção da abordagem ou primícias de EA 
composição numa visão holística em relação à problemática socioambiental global, considerando aspectos políticos, éticos, sociais e ambientais, levando o ouvinte à criticidade sobre o assunto abordado. Sobre a concepção crítica da EA, esta visa descobrir as realidades socioambientais e transformar o que causa os problemas na sociedade (LEME, 2006). Acredita-se que isto possa ser um dos caminhos possíveis para o empoderamento dos cidadãos, pressupondo-se a formação de um sujeito crítico e transformador da realidade (CAVALCANTI-NETO; AMARAL, 2011).

Quadro 6: Letra musical que contém traços da EA crítica.

\begin{tabular}{|l|}
\hline \multicolumn{1}{|c|}{ Grupo Flor da cidade } \\
\hline O aquecimento global \\
Todos nós somos culpados \\
O que dá mais sofrimento \\
A gente vê pra todo lado \\
Ignorância, covardia, ganância, corrupção \\
Malandragem, falta de atitude, dureza de coração \\
Falta de respeito, assassinato, a grande destruição \\
Muita coisa acontecendo \\
Que não dá mais alegria \\
É uma tristeza que a ver \\
É a nossa democracia \\
Vamos pensar e analisar \\
A dignidade é coisa certa \\
Do jeito que tá o sofrimento \\
Deixa a nossa Terra em alerta \\
\end{tabular}

Fonte: Dados da pesquisa.

A música, assim como toda criação artística, por se tratar de uma manifestação e expressão do homem, torna-se um campo privilegiado para abordar questões e temas importantes que fazem parte do cotidiano, podendo ser influenciada por aspectos sociais, políticos, econômicos, culturais e de relações humanas (VIEIRA; HENNING, 2012). Deste modo, a arte pode ser um importante canal de transmissão de conhecimentos locais, a fim de influenciar mentalidades e atitudes. Nesse caso, exemplifica-se a utilização das histórias em quadrinhos de $A$ Turma do Açaí como um veículo de comunicação que facilita a socialização de conceitos ao leitor sobre a problemática ambiental que decorre do modo de vida da população, além de valorizar a cultura regional paraense (SILVA et al. 2013). 


\section{Conclusões}

As letras musicais estudadas do carimbó de Marapanim-PA são, em sua maioria, relacionadas ao modo de vida do povo amazônico. O carimbó, enquanto manifestação cultural local, é expresso por meio da dança, música e poeticidade, referindo-se ao cotidiano do homem que trabalha na roça e na pesca, além de sua religiosidade e crença.

Nas composições musicais a natureza local e regional é fonte de inspiração e digna de contemplação e proteção. É tida como espaço da biodiversidade, de moradia e das relações de sobrevivência humana, mas que passam por problemas socioambientais decorrentes das ações antrópicas da própria população.

Geralmente, encontram-se nos versos musicais indícios de Educação Ambiental que visam principalmente a conscientização ecológica dos ouvintes para a conservação/preservação do meio ambiente, podendo ser um importante instrumento de difusão e debate da EA nos meios formais, não formais e informais de ensino.

\section{Agradecimentos}

Aos representantes dos grupos de carimbó de Marapanim: Japiim, Os originais, Flor do Mangue e Flor da cidade que se disponibilizaram em colaborar com o presente estudo.

\section{Referências}

BEZERRA, N.R.C. A Amazônia e os novos paradigmas de desenvolvimento rural: uma breve reflexão teórica. Revista Brasileira de Agroecologia, Cruz Alta, v. 6, n. 2, p. 40-54, 2011.

BLANCO, S.M.R. O Carimbó em Algodoal e seus aspectos sócio-gráficos. Anais do $\mathrm{V}$ Congresso Latino-americano da Associação Internacional para o Estudo da Música Popular, Rio de Janeiro, p. 1-7, 2004.

BRASIL. Ata da $7^{a}$ Reunião do Conselho Consultivo do Patrimônio Cultural, de 11 de setembro de 2014. Brasília, 2014. Disponível em: http://portal.jphan.gov.br/uploads/atas/20140276 Reuniao Ordinaria 11 de s etembro.pdf. Acesso em: 14 set. 2015.

CAMPELO, L.C.H.; ALMEIDA, R.H. Dona Onete e o imaginário folk-Amazônico. Revista Internacional de Folkcomunicação, Ponta Grossa, v. 10, n. 21, p. 107-123, 2012.

CAVALCANTI-NETO, A.L.G.; AMARAL, E.M.R. Análise de concepções e visões de professores de ciências sobre educação ambiental. Pesquisa em Educação Ambiental, São Paulo, v. 6, n. 2, p. 119-136, 2011. 
COSTA, T.L. Música, literatura e identidade amazônica no século XX: o caso do carimbó no Pará. Artcultura, Uberlândia, v. 12, n. 20, 2010.

COSTA, T.L. Carimbó e Brega: Indústria cultural e tradição na música popular do norte do Brasil. Revista Estudos Amazônicos, Belém, v. 6, n. 1, p. 149177, 2011.

FONSECA, F.S.R.; OLIVEIRA, L.G. Concepções de meio ambiente dos educadores ambientais do Zoológico de Goiânia: implicações nas atividades e contribuições para a formação do sujeito ecológico? Educar em Revista, Curitiba, n. 41, p. 231-246, 2011.

FURTADO, L.G.; NASCIMENTO, I.H.; SANTANA, G.; MANESCHY, M.C. Formas de utilização de manguezais no litoral do Estado do Pará: casos de Marapanim e São Caetano de Odivelas. Revista Amazônia: Ciência \& Desenvolvimento, Belém, v. 1, n. 2, p. 113-127, 2006.

FUSCALDO, B.M.H. O carimbó: cultura tradicional paraense, patrimônio imaterial do Brasil. Revista CPC, São Paulo, n. 18, p. 81-105, 2015.

GABAY, M. A conquista do Amazonas: carimbó e jogo identitário no Pará. Anais IV Encontro de Pesquisadores em Comunicação e Música Popular, São Paulo, p. 1-14, 2012.

GOMES, G.W.B. Festa híbrida: festividade de carimbó de São Benedito como processo comunicacional na Amazônia. Razón y palabra, n. 77, p. 1-13, 2011.

JASTES, É. Dinâmica cultural nas danças tradicionais da Amazônia. Revista Ensaio Geral, Belém, v.1, n.1, p. 1-6, 2009.

LEME, T.N. Os conhecimentos práticos dos professores: (re)abrindo caminhos para a educação ambiental na escola. São Paulo: Annablume, 2006.

LOUREIRO, C.F.B. Educação ambiental e movimentos sociais na construção da Cidadania ecológica e planetária. In: LOUREIRO, C.F.B.; LAYRARGUES, P.P.; CASTRO, R.S. (Orgs.) Educação Ambiental: repensando o espaço da cidadania. 2 ${ }^{\mathrm{a}}$ ed. São Paulo: Cortez, 2002.

MARIN, A.A.; PEREIRA, C.A. Sons, corpo, sensibilização: diálogos entre a música e a Educação Ambiental. Revista Eletrônica do Mestrado de Educação Ambiental, Rio Grande, v. 22, n. 1, p. 401-416, 2009.

MARPICA, N.S. 169f. 2008. As questões em livros didáticos de diferentes disciplinas da quinta série do ensino fundamental. Dissertação (Mestrado em Educação). Centro de Educação e Ciências Humanas, Universidade Federal de São Carlos, São Carlos, 2008.

MINISTÉRIO DO MEIO AMBIENTE - MMA. Estudo socioambiental referente à proposta de criação de reserva extrativista marinha no município de Marapanim, estado do Pará, p. 1-103, 2014. Disponível em: http://www.icmbio.gov.br/portal/images/stories/o-que-

fazemos/consultas publicas/Estudo Socioambiental Cria\%C3\%A7\%C3\%A3o de Resex em Marapanim PA 2.pdf. Acesso em: 14 set. 2015. 
MONTEIRO, V.P. Tambores da floresta: o estudo da performance do tambor carimbó no carimbó de Salinópolis, no Estado do Pará. Anais do Simpósio Brasileiro de Pós-Graduandos em Música, Rio de Janeiro, v. 2, n. 2, p. 934944, 2012.

NABAES, T.O. Natureza social e apreciação musical: considerações. Revista Eletrônica do Mestrado de Educação Ambiental, Rio Grande, v. 21, n. 2, p. 217-226, 2008.

SAUVÉ, L. Uma cartografia das correntes em educação ambiental. Educação ambiental: pesquisa e desafios. Porto Alegre: Artmed, p. 17-44, 2005.

SILVA, R.L.F.; CAMPINA, N.N. Concepções de educação ambiental na mídia e em práticas escolares: contribuições de uma tipologia. Pesquisa em Educação Ambiental, São Paulo, v. 6, n. 1, p. 29-46, 2011.

SILVA, L.M. et al. Educação ambiental a partir da valorização da cultura regional do estado do Pará. Revista Eletrônica do Mestrado de Educação Ambiental, Rio Grande, v. 30, n. 2, p. 290-303, 2013.

VIEIRA, V.T.; HENNING, P.C. Atravessamentos culturais e crise ambiental na atualidade: modos ecológicos de vida no rock'n roll. Revista Eletrônica do Mestrado de Educação Ambiental, Rio Grande, v. 28, n. 1, p. 434-448, 2012. 